\title{
Efektivitas Buah Maja (Aegle Marmelos (L.) Corr.) sebagai Bahan Pembersih Logam Besi
}

\author{
Ira Fatmawati \\ Balai Pelestarian Cagar Budaya Jawa Timur
}

\begin{abstract}
Abstrak: Buah Maja (Aegle marmelos (L.) Corr.) identik dengan sebuah kerajaan yang pernah berjaya pada abad XIII - XV, yaitu Kerajaan Majapahit. Ciri khas yang dimiliki buah Maja adalah dagingnya berwarna putih dan kulitnya berwarna hijau muda. Hingga kini, buah yang berasa manis ini masih banyak dijumpai di daerah Mojokerto, Jawa Timur. Beberapa senyawa kimia yang terkandung di dalam buah Maja, antara lain : marmelosin (C13H12O3), minyak atsiri, pektin, saponin, tanin, dan2-furocoumarins-psoralen. Adanya sifat asam dalam daging buah menjadikan Maja dapat digunakan sebagai pembersih logam besi. Penelitian ini dilakukan untuk menguji efektivitas antara buah Maja muda dan tua sebagai bahan pembersih logam besi. Metode yang digunakan adalah sampel sabit berbahan besi ditimbun dalam daging buah Maja selama 1 x 24 jam, 2 x 24 jam, 3 × 24 jam, dan 4 x 24 jam. Berdasarkan hasil penelitian pada sampel sabit yang ditimbun selama 4 x 24 jam dalam buah Maja tua menunjukkan bahwa sampel terlihat lebih bersih dibandingkan sampel yang ditimbun dalam buah Maja muda. Ini menunjukkan bahwa buah Maja tua lebih efektif sebagai bahan pembersih untuk logam besi.
\end{abstract}

Kata kunci : besi, buah Maja, dan sabit

\begin{abstract}
Maja fruit (Aegle marmelos (L.) Corr.) is identic to an empire that had triumphed in XIII - XV century, namely the Majapahit Kingdom. The characteristic of Maja fruit is white flesh and light green skin. Until now, the sweet taste of this fruit can be found in the area of Mojokerto, East Java Province. Some chemical compounds in Maja fruit is marmelosin $\left(\mathrm{C}_{13} \mathrm{H}_{12} \mathrm{O}_{3}\right)$, essential oils, pectin, saponins, tannins, and2-furocoumarins-psoralen. The acidic nature in flesh of fruit makes Maja can be used as a cleansing for ferrous metals. This study was conducted to test the effectiveness between young and old Maja fruit as a cleansingfor ferrous metals. The method used is sickle samples was made from iron stockpiled in flesh of Maja for $1 \times 24$ hours, $2 \times 24$ hours, $3 \times 24$ hours, and 4 × 24 hours. Based on the results of research on sickle samples were stockpiled for 4 × 24 hours in old Maja fruit showed that the samples looks cleaner than the samples stockpiled in young Maja fruit. It shows that the old Maja fruit is more effective as a cleansing for ferrous metals.
\end{abstract}

Keywords : iron, Maja fruit, and sickle

\section{Pendahuluan}

\section{Latar Belakang}

Museum Majapahit yang berada di bawah naungan Balai Pelestarian Cagar Budaya Mojokerto Wilayah Kerja Provinsi Jawa Timur memiliki koleksi benda cagar budaya hasil dari hibah, temuan,maupun ekskavasi situs-situs di Jawa Timur. Jenis bahan penyusun dari koleksi-koleksi tersebut beragam mulai dari kayu, logam, keramik, terakota, batu, bata, dan tulang. Di antara koleksi-koleksi tersebut, yang cukup menarik untuk diteliti adalah koleksi berbahan logam yang didominasi oleh unsur besi. Belajar dari kearifan tradisional masyarakat dahulu dalam membersihkan peralatan berbahan logam, maka dalam memelihara cagar budaya perlu juga dikembangkan cara-cara tradisional yang lebih efektif, aman, reversibel, ekonomis, dan ramah lingkungan. Oleh karena itu, dalam penelitian ini dilakukan pengujian pembersihan logam besi menggunakan buah Maja.

Beberapa hal yang perlu dipertimbangkan sebelum melakukan suatu penelitian adalah melihat ketersediaan bahan, sampel, dan peralatan yang akan digunakan. Daerah Trowulan yang masuk dalam kabupaten Mojokerto identik dengan cerita Kerajaan Majapahit yang pernah berjaya sekitar abad XIII - XV. Kata Majapahit itu sendiri berasal dari dua kata, yaitu : Maja dan pahit yang artinya buah Maja yang rasanya pahit. Dalam nama kerajaan tersebut secara jelas menyebutkan buah Maja yang menunjukkan bahwa buah ini sangat mudah ditemui di daerah tersebut. Dan ternyata hingga saat ini buah Maja banyak dijumpai di daerah Trowulan. Berkaitan dengan sejarah kerajaan Majapahit, ada baiknya jika buah Maja yang menjadi inspirasi sebuah nama kerajaan tersebut juga menjadi inspirasi dalam pelestarian cagar budaya tinggalan dari kerajaan itu. Oleh karena 
itu, keefektivan buah Maja perlu dieksplorasi secara mendalam sehingga tidak hanya sekedar digunakan sebagai sebuah nama. Namun, ada banyak manfaat yang bisa didapat dari buahnya secara nyata. Inilah yang mendasari pemilihan buah Maja untuk digunakan dalam penelitian pembersihan logam besi.

\section{Rumusan Masalah}

a. Seberapa efektifkah buah Maja sebagai bahan pembersih besi?

b. Apakah umur buah Maja mempengaruhi keefektivannya?

c. Apakah lamanya waktu penimbunan mempengaruhi tingkat kebersihan besi?

\section{Tujuan Penelitian}

a. Mengetahui keefektivan buah Maja sebagai bahan pembersih besi

b. Menentukan metode pembersihan besi yang paling efektif menggunakan buah Maja

\section{I.4 Manfaat Penelitian}

a. Hasil penelitian diharapkan dapat dijadikan sebagai metode alternatif pembersihan besi yang efektif, efisien, aman, ekonomis, reversibel, dan ramah lingkungan

b. Mengurangi penggunaan bahan kimia sintetis yang terkadang menimbulkan dampak negatif terhadap cagar budaya

\section{TINJAUAN PUSTAKA}

\section{II.1 Maja}

Aegle marmelos (L.) Corr.merupakan tanaman yang biasa dikenal sebagai Maja memiliki sebutan beragam di tiap daerah, antara lain : Mojo atau Mojo legi (Jawa), Maos (Madura), Bilak (Melayu), danKabila (Alor, Nusa Tenggara). Tanaman ini
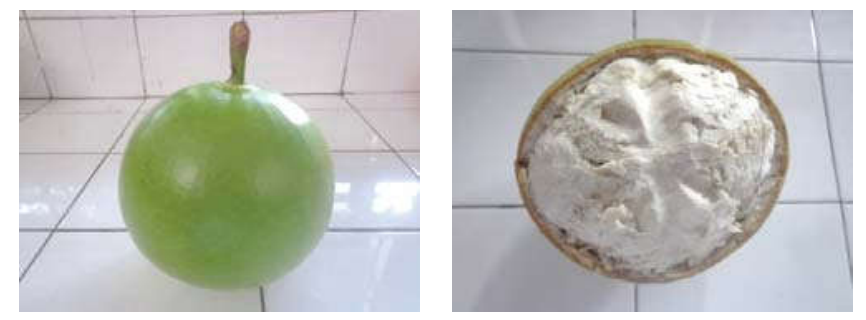

Foto 1 :

Kulit dan daging buah Maja diklasifikasikan ke dalam Divisi Spermatophyta, Sub Divisi Angiospermae, Kelas Dicotyledoneae, Bangsa Rutales, Suku Rutaceae, dan Marga Aegle. Selain di Indonesia, ternyata Maja juga dapat dijumpai di wilayah Asia Tenggara lainnya dan Asia Selatan. Daerah penyebarannya terutama di dataran rendah hingga ketinggian $\pm 500 \mathrm{~m}$ di atas permukaan laut dengan kondisi lahan basah seperti rawa-rawa maupun di lahan kering, dan pada suhu $49^{\circ} \mathrm{C}$ saat musim kemarau atau $-7^{\circ} \mathrm{C}$ saat musim dingin.

Pohon Maja dapat tumbuh sampai 20 $\mathrm{m}$ dengan tajuk yang tumbuh menjulang ke atas. Bunganya harum hingga aroma wanginya bisa tercium dari jarak yang cukup jauh. Tanaman ini mulai berbuah pada umur 5 tahun dan produksi maksimal dicapai setelah umur15 tahun. Satu pohon bisa menghasilkan $200-400$ butir buah. Buah Maja biasanya masak pada musim kemarau bersamaan dengan daun-daunnya yang meluruh. Bentuk buah seperti bola voli memiliki diameter $5-12 \mathrm{~cm}$, kulit buah berwarna hijau dan keras, dagingnya putih dan berbau harum serta manis rasanya. Buah ini sering kali dianggap sama dengan Berenuk (Crescentia cujete L.) yang juga memiliki kulit buah berwarna hijau namun dagingnya berasa pahit.

Menurut Hariana (2008), beberapa bahan kimia yang terkandung dalam Maja di antaranya, zat lemak dan minyak terbang yang mengandung linonen. Daging buah Maja mengandung 2-furocoumarins-psoralen dan marmelosin $\left(\mathrm{C}_{13} \mathrm{H}_{12} \mathrm{O}_{3}\right)$. Buah, akar, dan daun Maja bersifat antibiotik. Selain itu, akar, daun, dan ranting digunakan untuk mengobati gigitan ular. Akar Maja mengandung psoralen, anthotoxin, o-methylscopoletin, scopoletin, decursinol, haplonine, dan aegelinol. Daun Maja mengandung a-limonene, 56\%-a- $\delta$-phellandzene, sineol, 17\% cyrnene, citonellol, citiol, 5\% cumin aldehyde, alkaloids, o-(3,3-dimethylallyl)-balfordinol, n-2-ethoxy2-(4-methoxyphenyl) ethylcinnamide, n-2-methoxy-2-[43,3-dimethyalloxy) phennyl, ethylcinnamide, dan n-2methoxy-2-(4-methoxyphenyl)-ethylcinnamamide.

Sedangkan menurut Rismayani (2013), buah Maja selain mengandung marmelosin juga 
minyak atsiri, pektin, saponin, dan tanin. Senyawa saponin merupakan glikosida yang memiliki aglikon berupa steroid dan triterpenoid. Saponin steroid tersusun atas inti steroid $\left(\mathrm{C}_{27}\right)$ dengan molekul karbohidrat. Steroid saponin dihidrolisis menghasilkan suatu aglikon yang dikenal sebagai saraponin. Saponin triterpenoid tersusun atas inti triterpenoid dengan molekul karbohidrat dan apabila dihidrolisis menghasilkan suatu aglikon yang disebut sapogenin. Molekul yang dimiliki oleh senyawa saponin inilah menyebabkan buah Maja berbusa, mempunyai sifat antieksudatif, inflamatori, dan haemolisis (merusak sel darah merah).

\section{2 Besi}

Salah satu unsur kimia yang cukup melimpah di kulit bumi adalah besi yang disimbolkan dengan Fe. Besi yang memiliki nomor atom 26 dan massa atom relatif sebesar 55,845 gram/mol tersebut merupakan logam transisi dalam tabel periodik.Beberapa sifat umum besi antara lain : berbentuk padat, massa jenis (mendekati suhu kamar) : 7,874 gram $/ \mathrm{cm}^{3}$ dan massa jenis (cairan pada titik lebur) : 6,98 gram/ $\mathrm{cm}^{3}$, titik lebur : $1538^{\circ} \mathrm{C}$, titik didih : $2862^{\circ} \mathrm{C}$, dan nilai potensial energi untuk $\mathrm{Fe}^{2+}$ sebesar-0,89 Volt.

Meskipun kelimpahannya cukup tinggi, namun besi memiliki kelemahan, yaitu mudah mengalami korosi akibat reaksi oksidasi dengan lingkungan yang faktor utamanya adalah adanya air dan udara di sekitarnya sehingga menimbulkan kerugian karena mengurangi umur pakai dari benda yang terbuat dari bahan tersebut. Mekanisme reaksi terjadinya korosi adalah besi yang letaknya jauh dari permukaan apabila bereaksi dengan udara akan dioksidasi oleh ion $\mathrm{Fe}^{2+}$ dan ion ini larut dalam air. Sebagian oksigen dari udara larut dalam air dan mengoksidasi $\mathrm{Fe}^{2+}$ menjadi $\mathrm{Fe}^{3+}$ sehingga membentuk karat $\left(\mathrm{Fe}_{2} \mathrm{O}_{3} \cdot \mathrm{H}_{2} \mathrm{O}\right)$.

Menurut Hamilton (1999) dalam Cahyandaru (2013), korosi besi terjadi karena sifat logamnya yang mudah teroksidasi dan banyaknya senyawa-senyawa terlarut dalam air. Keberadaan oksigen mempengaruhi proses korosi meskipun dalam kondisi tanpa oksigen pun korosi juga dapat berlangsung. Dalam kondisi air yang mengandung oksigen, mekanisme reaksi kimia yang terjadi adalah :

$\mathrm{FeCl}_{2}+2 \mathrm{NaOH} \longrightarrow \mathrm{Fe}(\mathrm{OH})_{2}+2 \mathrm{NaCl}$

Senyawa hidroksida yang terbentuk pada larutan yang mengandung oksigen akan mengalami reaksi sekunder dengan terbentuknya endapan korosi di sekitar permukaan logam bagian anoda.

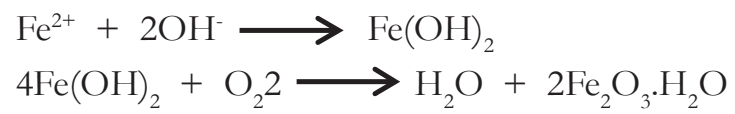

Reaksi sekunder yang melibatkan ion feri menghasilkan produk lain dari korosi, yaitu :

$$
\begin{aligned}
& 6 \mathrm{Fe}(\mathrm{OH})_{2}+\mathrm{O}_{2} \longrightarrow 4 \mathrm{H}_{2} \mathrm{O}+2 \mathrm{Fe}_{3} \mathrm{O}_{4} \cdot \mathrm{H}_{2} \mathrm{O} \\
& \text { (green bydrated magnetite) } \\
& \mathrm{Fe}_{3} \mathrm{O}_{4} \cdot \mathrm{H}_{2} \mathrm{O} \longrightarrow \mathrm{H}_{2} \mathrm{O}+\mathrm{Fe}_{3} \mathrm{O}_{4} \\
& \text { (black magnetite) }
\end{aligned}
$$

Produk-produk reaksi korosi dapat bervariasi bergantung pada kondisi lingkungan logam besi tersebut berada. Lapisan-lapisan korosi paling umum yang dapat terjadi pada permukaan besi adalah :

$\mathrm{Fe}_{3} \mathrm{O}_{4} / 2 \mathrm{Fe}_{3} \mathrm{O}_{4} \cdot \mathrm{H}_{2} \mathrm{O}$ atau $2 \mathrm{Fe}_{2} \mathrm{O}_{3} \cdot \mathrm{H}_{2} \mathrm{O}$

Mekanisme reaksi kimia korosi pada kondisi anaerobik atau kondisi tanpa oksigen melibatkan aktivitas bakteri pereduksi sulfat yang umum ditemukan pada perairan bergaram (laut), air tawar, atau tanah berair. Aktivitas pelapukan awal menggunakan oksigen sehingga pada bagian-bagian tertentu terdapat lokasi yang tidak mengandung oksigen. Bakteri yang hidup tanpa oksigen akan menggunakan sulfat sebagai sumber metabolismenya dengan reaksi sebagai berikut :

$$
\mathrm{H}_{2} \mathrm{SO}_{4}+8 \mathrm{H}^{+} \longrightarrow \mathrm{H}_{2} \mathrm{~S}+4 \mathrm{H}_{2} \mathrm{O}
$$

Hidrogen sulfida akan bereaksi dengan besi menghasilkan korosi Besi sulfida dan Besi hidroksida seperti reaksi kimia di bawah ini : 


$$
\begin{aligned}
& \mathrm{Fe}^{2+}+\mathrm{H}_{2} \mathrm{~S} \longrightarrow \mathrm{FeS}+2 \mathrm{H}^{+} \\
& 3 \mathrm{Fe}^{2+}+6 \mathrm{OH}^{-} \longrightarrow 3 \mathrm{Fe}(\mathrm{OH})_{2} \\
& 4 \mathrm{Fe}+\mathrm{H}_{2} \mathrm{SO}_{4}+2 \mathrm{H}_{2} \mathrm{O} \longrightarrow \mathrm{FeS}+3 \mathrm{Fe}(\mathrm{OH})_{2}
\end{aligned}
$$

\section{METODE PENELITIAN}

Sampel yang digunakan dalam penelitian ini adalah sabit berbahan besi yang merupakan benda bukan cagar budaya. Sebelum melakukan penelitian, terlebih dahulu dilakukan pemilihan sampel, yaitu sabit tersebut telah mengalami korosi hampir di seluruh permukaannya. Selanjutnya sampel dibersihkan dari kotoran yang menempel di permukaan menggunakan sikat. Bahan, alat, dan prosedur penelitian dapat dijelaskan sebagai berikut :

Bahan :

1. Buah Maja

2. Air

Alat :

1. Nampan plastik

2. Pisau

3. Sikat

4. Sarung tangan

Prosedur :

1. Buah Maja dipotong menjadi dua bagian kemudian daging buahnya diambil dengan cara dikerok menggunakan sendok sehingga diperoleh tekstur yang halus. Daging buah yang telah halus diletakkan di dalam nampan bersih.

2. Sampel yang telah didokumentasi selanjutnya diletakkan di atas daging buah Maja sambil ditekan dan diatur sedemikian rupa sehingga seluruh permukaan sampel tertimbun dalam daging buah tersebut. Hal ini bertujuan agar kandungan senyawa kimia yang terdapat dalam daging buah Maja dapat bereaksi secara maksimal di seluruh permukaan sampel.

3. Sampel ditimbun dalam daging buah Maja selama $1 \times 24$ jam. Selama penimbunan, nampan berisi sampel dan daging buah Maja ditutup dengan plastik. Setelah waktu penimbunan tercapai, sampel diangkat dan dibilas air mengalir sambil disikat kemudian dikeringkan di udara terbuka.

4. Setelah kering, sampel didokumentasi untuk mengetahui perbedaan hasil di tiap perlakuannya.

5. Sampel yang sama ditimbun lagi dalam daging buah Maja yang masih fresh mengikuti prosedur pada poin 2

dan dilanjutkan hingga poin 4. Perlakuan ini dilakukan hingga penimbunan mencapai waktu 4 x 24 jam.

\section{ANALISIS HASIL PENELITIAN}

Berdasarkan umurnya, buah Maja dapat dibedakan sifat fisik dan kimianya. Buah Maja muda memiliki tempurung yang lunak, daging buah cenderung putih dan agak keras, serta nilai $\mathrm{pH}$-nya 5. Sedangkan buah Maja tua memiliki tempurung yang keras, daging buah berwarna putih kekuningan dan lunak, serta nilai pH-nya 4. Dalam penelitian ini, buah Maja yang dipilih dibedakan umurnya untuk mengetahui perbedaan tingkat keefektivannya sebagai bahan pembersih logam besi.

Buah Maja yang baru dipetik dapat langsung dibelah untuk diambil daging buahnya. Apabila rentang waktu antara pemetikan buah dan pengambilan daging buah terlalu lama, maka daging buah akan berwarna hitam. Oleh karena itu, sebaiknya buah dipetik sehari sebelum daging buah digunakan untuk membersihkan besi. Daging buah yang berserat dan berasa manis itu apabila dihaluskan dengan cara diremas akan menghasilkan buih berwarna putih dan bau harum yang khas dari buah tersebut. Namun, ketika daging buah dibiarkan di udara terbuka selama beberapa saat, maka daging buah yang awalnya berwarna putih akan berubah menjadi hitam dengan bau yang kurang sedap. Terdapat sedikit perbedaan antara daging buah Maja muda dan tua. Pada daging buah Maja muda, setelah dilakukan perlakuan selama 24 jam, daging buahnya tetap harum dan sebagian masih berwarna putih. Sedangkan pada daging buah Maja tua, setelah dilakukan perlakuan selama 24 jam, daging buahnya berbau kurang sedap dan seluruh daging buahnya berwarna hitam.

Setiap perlakuan sampel membutuhkan satu buah Maja yang daging buahnya rata-rata bermassa 1000 - 1200 gram. Buah Maja yang digunakan merupakan buah yang baru dipetik. Selanjutnya, buah tersebut

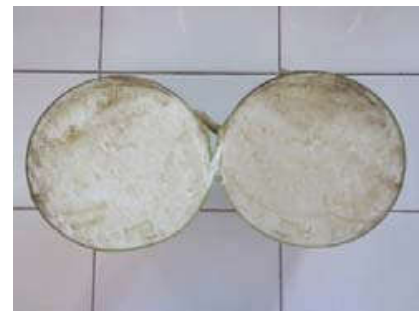

Foto 2 :

Daging buah Maja muda (kiri) dan tua (kanan) 


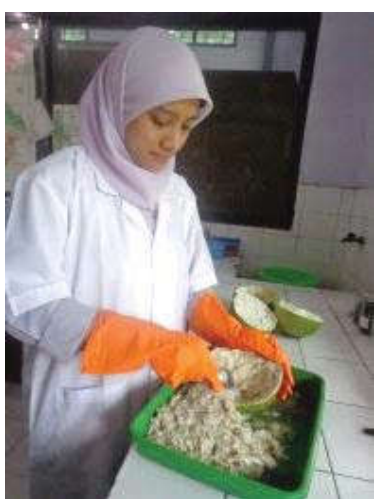

Foto 3 :

Persiapan bahan

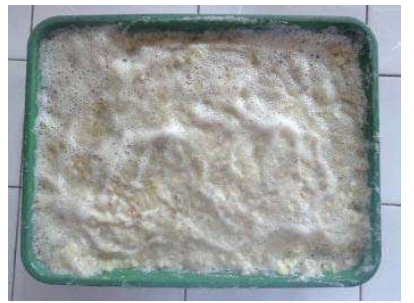

Foto 4 :

Daging buah Maja yang telah dihaluskan

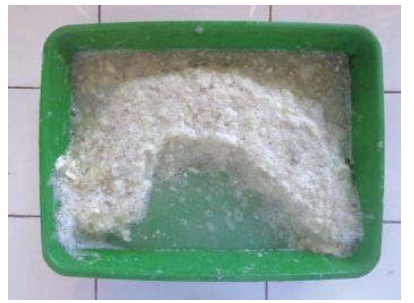

Foto 5 :

Proses penimbunan sampel

dibelah menjadi dua bagian dan diambil daging buahnya kemudian dihaluskan dengan cara diremas. Dalam memasukkan sampel sebaiknya nampan diisi daging buah terlebih dahulu kemudian sampel diletakkan di atasnya dan sisa daging buah yang ada diletakkan di atas sampel sehingga seluruh permukaan sampel tertimbun oleh daging buah seperti terlihat pada foto 5 di atas. Hal ini dilakukan agar kandungan senyawa kimia buah Maja dapat bereaksi secara maksimal di kedua sisi permukaan besi yang terkorosi tersebut.

Dalam penelitian ini digunakan dua jenis buah Maja, yaitu : buah Maja muda yang berumur \pm 1 bulan dan buah Maja tua yang berumur \pm 2 bulan. Metode yang digunakan adalah sampel ditimbun dalam daging buah Maja dengan variasi waktu penimbunan selama 1 x 24 jam, 2 x 24 jam, 3 x 24 jam, dan 4 x 24 jam. Setiap perlakuan menggunakan jenis buah yang sama, artinya buah Maja muda dan tua tidak dicampur selama proses penimbunan. Selama penimbunan, nampan yang berisi sampel dan daging buah Maja ditutup plastik agar tidak bereaksi dengan udara. Ketika waktu penimbunan tepat 24 jam, sampel diangkat dan dibilas air mengalir sambil disikat kemudian dikeringkan di udara terbuka. Untuk mengetahui perbedaan hasil di tiap perlakuan, maka diperlukan dokumentasi sampel sebelum dan setelah perlakuan. Selanjutnya, sampel yang sama ditimbun kembali dalam buah Maja yang masih fresh dan dibiarkan selama 24 jam. Prosedur dilanjutkan hingga pengeringan sampel. Perlakuan ini dilakukan secara berkelanjutan hingga mencapai waktu penimbunan selama 4 x 24 jam. Hasil pembersihan sampel besi menggunakan buah Maja dapat dijelaskan sebagai berikut :

\section{Perlakuan I}

Pada penelitian ini, sampel yang digunakan berupa sabit berbahan besi yang telah mengalami korosi secara merata di kedua sisi permukaannya. Sampel tersebut ditimbun dalam buah Maja muda yang memiliki nilai $\mathrm{pH}$ 5. Berdasarkan data hasil penelitian yang tertera pada tabel di atas, sampel yang telah ditimbun selama $1 \times 24$ jam tidak mengalami banyak perubahan. Hal ini ditunjukkan dengan masih terlihatnya korosi berwarna merah kecoklatan di permukaan sampel. Seperti halnya penimbunan sebelumnya, pada penimbunan selama 2 x 24 jam juga tidak menunjukkan perbedaan yang signifikan, bahkan hasilnya masih tetap sama.

Setelah ditimbun selama 3 × 24 jam, salah satu permukaan sampel mulai terlihat sedikit warna putih

\section{Tabel 1 : Sampel besi yang ditimbun dalam daging buah Maja muda}

\begin{tabular}{|c|l|l|}
\hline NO. & PERLAKUAN & \\
\hline 1 & $\begin{array}{l}\text { Tanpa } \\
\text { perlakuan }\end{array}$ & \\
\hline 2 & Ditimbun \\
\hline 3 & \begin{tabular}{l}
$1 \times 24$ jam \\
\hline 5
\end{tabular} & Ditimbun \\
\hline 4 & $2 \times 24$ jam \\
\hline
\end{tabular}


keperakan sedangkan sisi lainnya belum menunjukkan perubahan. Perbedaan ini terjadi karena selama proses penimbunan, satu sisi permukaan sampel berada di atas sedangkan sisi lainnya berada di bawah. Dari penelitian yang telah dilakukan menunjukkan bahwa permukaan sampel yang berada di atas saat proses penimbunan menunjukkan hasil yang lebih bersih dibandingkan sisi lainnya yang berada di bawah. Selanjutnya, sampel yang sama ditimbun kembali dalam buah Maja yang masih fresh selama 4 x 24 jam. Perubahan yang terjadi di kedua sisi permukaan sampel menunjukkan hasil yang tidak signifikan dibanding penimbunan selama $3 \times 24$ jam. Ini menunjukkan bahwa senyawa kimia yang terkandung di dalam buah Maja muda bekerja secara lambat dan keefektivannya dipengaruhi oleh posisi sampel selama proses penimbunan.

\section{Perlakuan II}

Penelitian kedua menggunakan buah Maja tua yang memiliki nilai $\mathrm{pH} \mathrm{4,} \mathrm{yaitu} \mathrm{lebih} \mathrm{rendah}$ dibandingkan buah Maja muda. Sampel yang digunakan berupa sabit berbahan besi dengan kriteria yang sama dengan penelitian pertama, yaitu seluruh permukaannya telah mengalami korosi. Sampel yang awalnya mengalami korosi berwarna merah kecoklatan merata di seluruh permukaan sampel, mulai terlihat bersih setelah ditimbun selama 1 x 24 jam. Warna putih keperakan muncul di sebagian besar permukaan sampel meskipun masih ada bintik-bintik korosi berwarna coklat kehitaman. Kedua sisi permukaan sampel menunjukkan hasil yang sama meskipun salah satu permukaan sampel terlihat sedikit lebih bersih dibanding sisi lainnya.

Penimbunan sampel selama 2 x 24 jam menjadikan permukaan sampel bertambah bersih, warna putih keperakan semakin meluas terutama pada bagian pangkal dan tengah. Tingkat kebersihan sampel yang ditandai dengan warna putih keperakan semakin mendominasi hampir seluruh permukaan sampel setelah dilakukan penimbunan selama $3 \times 24$ jam. Dari penelitian yang telah dilakukan menunjukkan bahwa hasil perlakuan terlihat lebih optimal pada penimbunan selama 4 × 24 jam yang mana kedua sisi permukaan sampel terlihat lebih bersih dibanding perlakuan sebelumnya. Warna putih keperakan mendominasi seluruh permukaan sampel meskipun tidak seluruhnya. Ini menunjukkan bahwa
Tabel 2 : Sampel besi yang ditimbun dalam daging buah Maja tua

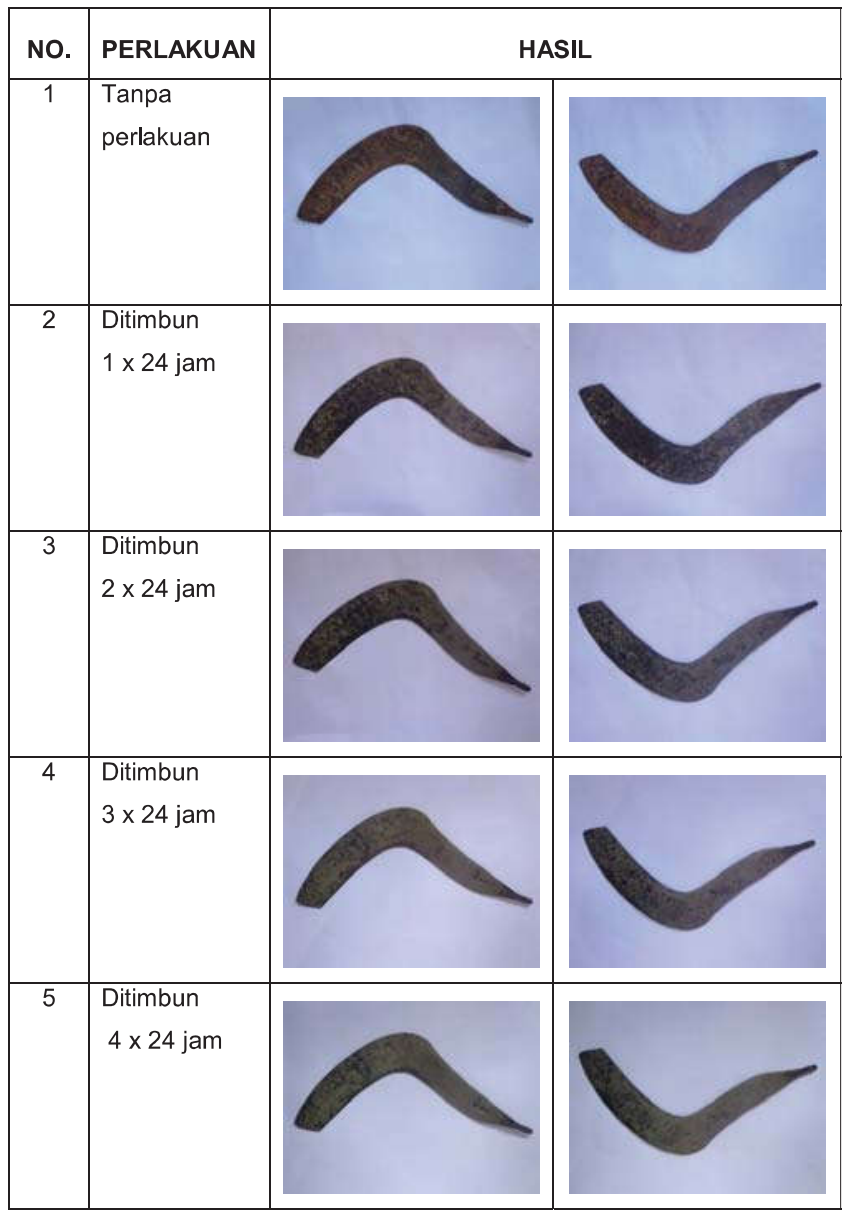

metode penimbunan ini efektif untuk mengurangi korosi yang terjadi pada logam besi.

Berdasarkan penelitian yang telah dilakukan pada sampel yang ditimbun dalam buah Maja muda dan tua menunjukkan hasil yang berbeda. Sampel yang ditimbun dalam buah Maja muda korosinya berkurang secara lambat dan hampir tidak terlihat perubahannya. Sedangkan sampel yang ditimbun dalam buah Maja tua terlihat perbedaan yang signifikan di setiap perlakuannya dan perubahan ini tidak hanya terjadi pada satu sisi permukaan sampel namun kedua sisi menunjukkan hasil yang sama. Ini menandakan bahwa keefektivan antara buah Maja muda dan tua jelas berbeda. Buah Maja tua lebih efektif sebagai bahan pembersih korosi besi dibandingkan buah Maja muda. Perbedaan keefektivan ini kemungkinan dipengaruhi oleh senyawa kimia yang terdapat di dalam kedua jenis buah Maja tersebut. Secara umum, kandungan senyawa kimia yang terdapat di dalam buah Maja adalah marmelosin, minyak atsiri, pektin, saponin, tanin, dan 2-furocoumarins-psoralen. Meskipun 
kandungan kimianya sama, namun perbedaan umur buah Maja kemungkinan mempengaruhi kuantitas dari beberapa kandungan senyawa kimia tersebut.

\section{PENUTUP}

\section{V.1 Simpulan}

Berdasarkan hasil penelitian pada sampel sabit berbahan besi yang dibersihkan dengan buah Maja untuk menghilangkan korosi yang melekat di permukaannya, maka dapat disimpulan bahwa :

1. Buah Maja tua lebih efektif mengurangi korosi pada kedua sisi permukaan sampel dibandingkan buah Maja yang masih berumur muda.

2. Posisi sampel saat penimbunan mempengaruhi tingkat kebersihannya. Permukaan sampel yang berada di atas cenderung lebih bersih dibandingkan permukaan sampel yang berada di bawah.

\section{Daftar Pustaka}

Anonim. 2013. Buah Maja. http://klinikpengobatanalami. wordpress.com diakses tanggal 27 Oktober 2014.

Anonim. Aegle marmelos (L) Corr. http:/ /www.e-bookspdf. org diakses tanggal 27 Oktober 2014.

Anonim. Mengenal Kandungan Kimia Buab Maja. http:// tipspetani.blogspot.com diakses tanggal 27 Oktober 2014.

Anonim. 2014. Besi. http://www.id.wikipedia.org diakses tanggal 30 Oktober 2014.

Anonim. 2014. Karat. http://www.id.wikipedia.org diakses tanggal 30 Oktober 2014.

Badan POM RI. 2008. Aegle marmelos (L.) Correa. http:// www.e-bookspdf.org diakses tanggal 27 Oktober 2014.

Cahyandaru, Nahar. 2013. Konservasi Cagar Budaya Logam. Makalah disampaikan dalam Pelatihan Tenaga Teknis Konservasi Tingkah Menengah di Balai Konservasi Borobudur tanggal 21 Agustus - 10 September 2013. Magelang : Balai Konservasi Borobudur.

Hamilton, DL. 1999. Methods of Conserving Archaeological Material from Underwater Sites. Conservation Research Laboratory. Texas : A \& M University.
3. Lamanya waktu penimbunan juga turut mempengaruhi keefektivan buah Maja. Sampel yang ditimbun dalam buah Maja selama 4 x 24 jam terlihat lebih bersih dibandingkan sampel yang hanya ditimbun selama $1 \times 24$ jam.

\section{V.2 Saran}

Penelitian ini hanya untuk menguji tingkat keefektivan antara buah Maja yang telah berumur tua dan yang masih berumur muda dengan melihat hasil penimbunannya. Perbedaan hasil penimbunan antara kedua jenis buah Maja tersebut tentunya berkaitan dengan senyawa kimia yang ada di dalamnya. Oleh kerena itu, kandungan senyawa kimia serta perbedaan kuantitasnya antara buah Maja tua dan muda perlu dilakukan penelitian lebih lanjut sehingga diperoleh penjelasan yang lebih ilmiah untuk mendukung hasil penelitian sebelumnya.

Hariana, Arief. 2008. Tumbuhan Obat dan Khasiatnya Seri 2. Depok : Penebar Swadaya.

Kartika, Rini; Sylvia Sjam; dan Untung Surapati. Bioaktivitas Ekstrak Agerathum conyzoides\%, Chromolaeana odorata, Aegle marmelos, dan Gliricidia sepium terhadap Penyakit Busuk Daun (Phytophthora palmivora) pada Tanaman Kakao di Kabupaten Bantaeng. Jurusan Hama dan Penyakit Tumbuhan. Fakultas Pertanian. Universitas Hasanuddin Makassar.

Rismayani. 2013. Manfaat Buah Maja sebagai Pestisida Nabati untuk. Hama Penggerek. Buah Kakao (Conopomorpha cramerella). Warta Penelitian dan Pengembangan Tanaman Industri, Volume 19 Nomor 3, Desember 2013. 